\title{
Fatty Aldehyde Dehydrogenases in Acinetobacter sp. Strain HO1-N: Role in Hexadecane and Hexadecanol Metabolism
}

\author{
M. E. SINGER AND W. R. FINNERTY* \\ Department of Microbiology, University of Georgia, Athens, Georgia 30602
}

Received 28 March 1985/Accepted 2 September 1985

\begin{abstract}
The role of fatty aldehyde dehydrogenases (FALDHs) in hexadecane and hexadecanol metabolism was studied in Acinetobacter sp. strain HO1-N. Two distinct FALDHs were demonstrated in Acinetobacter sp. strain HO1-N: (i) a membrane-bound, NADP-dependent FALDH activity induced 5-, 15-, and 9-fold by growth on hexadecanol, dodecyl aldehyde, and hexadecane, respectively, and (ii) a constitutive, NAD-dependent, membrane-localized FALDH. The NADP-dependent FALDH exhibited apparent $K_{m}$ and $V_{\max }$ values for decyl aldehyde of 5.0, 13.0, 18.0, and 18.3 $\mu \mathrm{M}$ and 537.0, 500.0, 25.0, and $38.0 \mathrm{nmol} / \mathrm{min}$ in hexadecane-, hexadecanol-, ethanol-, palmitate-grown cells, respectively. FALDH isozymes ald-a, ald-b, and ald-c were demonstrated by gel electrophoresis in extracts of hexadecane- and hexadecanol-grown cells. ald-a, ald-b, and ald-d were present in dodecyl aldehyde-grown cells, while palmitate-grown control cells contained ald-b and ald-d. Dodecyl aldehyde-negative mutants were isolated and grouped into two phenotypic classes based on growth: class 1 mutants were hexadecane and hexadecanol negative and class 2 mutants were hexadecane and hexadecanol positive. Specific activity of NADP-dependent FALDH in Ald21 (class 1 mutant) was 85\% lower than that of wild-type FALDH, while the specific activity of Ald24 (class 2 mutant) was $55 \%$ greater than that of wild-type FALDH. Ald21R, a dodecyl aldehyde-positive revertant able to grow on hexadecane, hexadecanol, and dodecyl aldehyde, exhibited a $100 \%$ increase in the specific activity of the NADP-dependent FALDH. The oxidation of $\left[{ }^{3} \mathrm{H}\right]$ hexadecane by Ald21 yielded the accumulation of $61 \%$ more fatty aldehyde than the wild type, while Ald24 accumulated $27 \%$ more fatty aldehyde, $95 \%$ more fatty alcohol, and $65 \%$ more wax ester than the wild type. This study provides genetic and physiological evidence for the role of fatty aldehyde as an essential metabolic intermediate and NADP-dependent FALDH as a key enzyme in the dissimilation of hexadecane, hexadecanol, and dodecyl aldehyde in Acinetobacter sp. strain HO1-N.
\end{abstract}

Aldehydes are considered metabolic intermediates in microbial alkane dissimilation, with aldehydes oxidized to fatty acid via aldehyde dehydrogenase (13). Aldehyde dehydrogenases have been described in a number of hydrocarbon-utilizing microorganisms, including Candida tropicalis (5, 6, 9, 10, 17), Candida intermedia (11), Pseudomonas aeruginosa $(3,8)$, Pseudomonas putida (oleovorans) (2), and Acinetobacter calcoaceticus $69 \mathrm{~V}$ (1, 15, 16). Sorger and Aurich (16) have reviewed the kinetic properties and cofactor requirements of several microbial aldehyde dehydrogenases.

A. calcoaceticus $69 \mathrm{~V}$ contains a membrane-bound, NADP-dependent aldehyde dehydrogenase which is induced during growth on hexadecane or hexadecanol $(1,15,16)$. Acinetobacter $\mathrm{sp}$. strain HO1-N contains a soluble, NADlinked, ethanol-inducible acetylaldehyde dehydrogenase (ALDH) required for growth on ethanol (14). In this study, two distinct fatty aldehyde dehydrogenase (FALDH) activities were demonstrated in Acinetobacter sp. strain HO1-N: (i) a membrane-bound, NADP-dependent FALDH induced during growth on hexadecane, hexadecanol, and fatty aldehyde, and (ii) a constitutive, NAD-linked, membranelocalized FALDH.

\section{MATERIALS AND METHODS}

Chemicals. All chemicals were of reagent-grade quality or better. High-purity electrophoresis-grade chemicals were used for polyacrylamide gel electrophoresis.

\footnotetext{
* Corresponding author.
}

Organism and culture conditions. Acinetobacter sp. strain HO1-N was used exclusively in this study (12). Culture conditions are described in the accompanying paper (14).

Isolation of fatty aldehyde-negative mutants. Cells were mutagenized with $N$-methyl- $N^{\prime}$-nitro- $N$-nitrosoguanidine and were subjected to two cycles of cycloserine-ampicillin enrichment during growth on minimal medium supplemented with $0.2 \%$ (vol/vol) dodecyl aldehyde (Aldrich Chemical Co., Inc., Milwaukee, Wis.), as described in the accompanying paper (14). After the second enrichment cycle, cells were screened for growth on minimal medium agar plates supplemented with dodecyl aldehyde, which was supplied as a vapor from the liquid phase in the lid of the petri dish.

Preparation of cell extracts and cell fractionation. Cell lysis and fractionation procedures have been described previously (14).

Induction of enzyme activity in resting cell suspensions. Induction experiments were performed as described previously (14), with palmitate-grown cells exposed to $0.3 \%$ (vol/vol) hexadecane, $0.2 \%$ (wt/vol) hexadecanol, $0.3 \%$ ( $\mathrm{vol} / \mathrm{vol})$ ethanol, or $0.2 \%$ ( $\mathrm{vol} / \mathrm{vol})$ dodecyl aldehyde.

Enzyme assays. FALDH activity was determined spectrophotometrically by measuring the rate of NAD or NADP reduction, as described for the assay of alcohol dehydrogenase and ALDH in the accompanying paper (14), using $0.05 \mathrm{mM}$ decyl aldehyde (Aldrich) dissolved in $2.5 \%$ dimethylformamide as the substrate. Oxygen uptake rates were measured polarographically with a Yellow Springs Instrument model 53 oxygen monitor.

Polyacrylamide gel electrophoresis. Polyacrylamide gel electrophoresis was performed as described previously, us- 


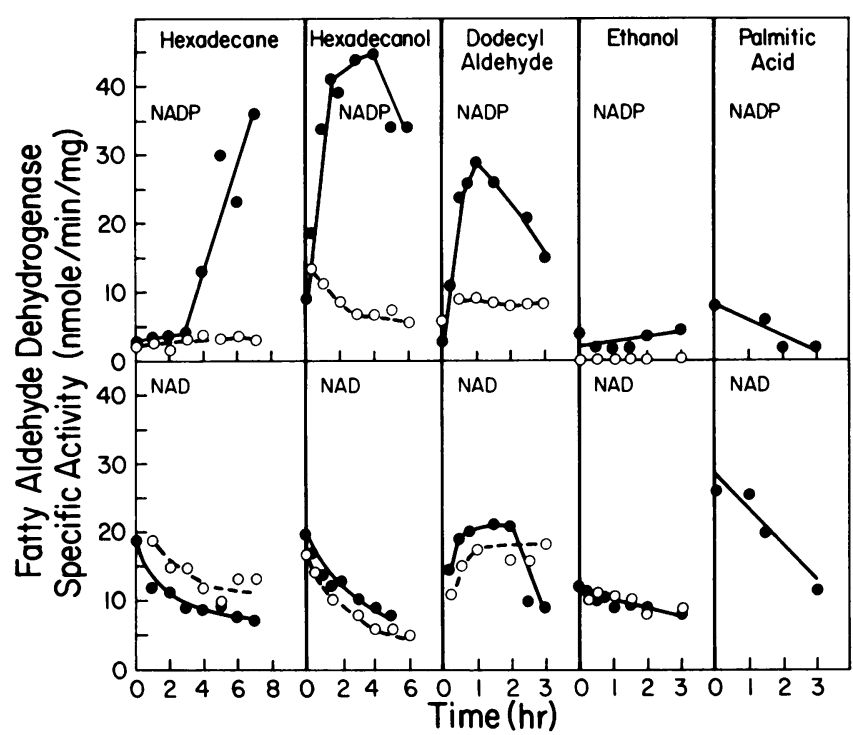

FIG. 1. Time course of NAD- and NADP-dependent FALDH activity in crude extracts of palmitate-grown cells exposed to the designated substrates $(\theta)$ and of cells preincubated for $15 \mathrm{~min}$ with $100 \mu \mathrm{g}$ of rifampin per $\mathrm{ml}(O)$.

ing nondenaturing gels (14). FALDH activity was localized in situ on gels by the method described for the detection of alcohol dehydrogenase activity (14), using $1.8 \%$ (vol/vol) acetylaldehyde (Sigma Chemical Co., St. Louis, Mo.) or $0.06 \%$ (vol/vol) decyl aldehyde as the substrate plus NAD or NADP as the cofactor.

$\left[{ }^{3} \mathbf{H}\right]$ hexadecane oxidation by intact cells. Nutrient brothyeast extract (NBYE)-grown cells were centrifuged at $25^{\circ} \mathrm{C}$ for $10 \mathrm{~min}$ at $8,000 \times g$ and were suspended in basal salts medium (pH 7.8) plus $\left[1,2-{ }^{3} \mathrm{H}\right]$ hexadecane (custom synthesized, $134 \mu \mathrm{Ci} / \mu \mathrm{mol}$; Mallinkrodt Inc., St. Louis, Mo.) diluted to a specific activity of $5.2 \mu \mathrm{Ci} / \mu \mathrm{mol}$ with $n$ hexadecane. Samples were removed after $24 \mathrm{~h}$ of shaking at $300 \mathrm{rpm}$ into chloroform-methanol $(2: 1$, vol/vol) for lipid extraction by the method of Folch et al. (4). Alkane was removed from the chloroform-soluble material by silicic acid column chromatography as previously described (12). Lipid extracts were analyzed by thin-layer chromatography to determine the radioactivity in specific neutral-lipid products. Neutral lipids were separated on activated Silica Gel G plates $(0.5 \mathrm{~mm})$ by development in petroleum ether-diethyl ether-glacial acetic acid $(70: 30: 1, \mathrm{vol} / \mathrm{vol} / \mathrm{vol})$. Lipids were detected with iodine vapors and tentatively identified by cochromatography with authentic standards, and the silica gel corresponding to each individual lipid was transferred to a scintillation vial for quantification of radioactivity. Portions of the lipid extract were saponified in $10 \%(\mathrm{wt} / \mathrm{vol})$ $\mathrm{KOH}$ in $80 \%$ (vol/vol) methanol for $2 \mathrm{~h}$ at $120^{\circ} \mathrm{C}$, acidified with $2 \mathrm{~N} \mathrm{HCl}$, extracted into diethyl ether, and analyzed by thin-layer chromatography to quantify the amount of radioactivity in fatty acid and fatty alcohol. The amount of radioactivity was measured with a Tracor Analytic 92 liquid scintillation counter.

\section{RESULTS}

FALDHs in Acinetobacter sp. strain HO1-N. Aliphatic aldehydes, $\mathrm{C}_{2}$ to $\mathrm{C}_{16}$, were oxidized by enzymes in crude extracts obtained from cells after growth on hexadecane, hexadecanol, dodecyl aldehyde, ethanol, and palmitate These enzymes could use either NAD or NADP as a cofactor. FALDH was routinely quantified with decyl aldehyde, the substrate providing maximal FALDH activity.

Induction of FALDHs. The specific activities of the NADand NADP-dependent FALDHs were measured at intervals during exposure of palmitate-grown cells to hexadecane, hexadecanol, dodecyl aldehyde, and ethanol (Fig. 1). The specific activity of the NADP-linked FALDH increased 5-, 15-, and 9-fold in cells exposed to hexadecanol, dodecyl aldehyde, and hexadecane, respectively. FALDH induction occurred within $15 \mathrm{~min}$ in dodecyl aldehyde- and hexadecanol-exposed cells and in $3 \mathrm{~h}$ in hexadecane-exposed cells. Preincubation of cells with rifampin prevented FALDH induction in hexadecane-, hexadecanol-, and dodecyl aldehyde-exposed cells. In ethanol-exposed cells and in palmitate-grown cells, NADP-dependent FALDH activity remained constant and was not affected by rifampin treatment.

The specific activity of the NAD-dependent FALDH activity decreased threefold during cell exposure to hexadecane, hexadecanol, and palmitate (Fig. 1). Pretreatment of cells with rifampin had no effect on NAD-linked FALDH activity. In dodecyl aldehyde-exposed cells, NADdependent FALDH activity increased twofold within $30 \mathrm{~min}$ and was not affected by preincubation of cells with rifampin.

Intact palmitate-grown cells oxidized dodecyl aldehyde at the rate of $511 \mathrm{nmol}$ of oxygen consumed per min per $\mathrm{mg}$ of cell protein, without a significant lag period, while rifampintreated cells oxidized dodecyl aldehyde at the rate of 416 $\mathrm{nmol} / \mathrm{min}$ per $\mathrm{mg}$ of cell protein, indicating a level of constitutive oxidation of dodecyl aldehyde.

Localization of FALDHs. The NAD- and NADP-linked FALDH activities were detected in the membrane as well as in the soluble fractions of cell extracts (Table 1). In hexadecane- and dodecyl aldehyde-grown cells, both activities were predominantly membrane localized; while in hexadecanol- and ethanol-grown cells, both activities were detected predominantly in the soluble fractions. In palmitate-grown cells, the NAD-linked FALDH activity was primarily soluble, while the NADP-linked FALDH activity was membrane bound.

Thermal stability of FALDHs. Crude extracts derived from dodecyl aldehyde-exposed cells were incubated at $58^{\circ} \mathrm{C}$ to determine the thermal stability of NAD- and NADPdependent FALDH activities (Fig. 2). At temperatures below $58^{\circ} \mathrm{C}$, neither enzyme exhibited significant activity loss. The NADP-linked enzyme activity lost $50 \%$ of its original activity after $3.5 \mathrm{~h}$ at $58^{\circ} \mathrm{C}$, while the NAD-linked enzyme activity was stimulated under these conditions. The differ-

TABLE 1. Localization of FALDH activities in Acinetobacter sp. strain HO1-N

\begin{tabular}{|c|c|c|c|c|c|c|}
\hline \multirow{3}{*}{ Inducer substrate } & \multicolumn{6}{|c|}{ Sp act of FALDH $(\mathrm{nmol} / \mathrm{min} / \mathrm{mg}$ of protein) } \\
\hline & \multicolumn{2}{|c|}{$\begin{array}{l}\text { Crude extract } \\
\text { with: }\end{array}$} & \multicolumn{2}{|c|}{$\begin{array}{l}\text { Soluble frac- } \\
\text { tion with: }\end{array}$} & \multicolumn{2}{|c|}{$\begin{array}{c}\text { Membrane } \\
\text { fraction with: }\end{array}$} \\
\hline & NAD & $\overline{\text { NADP }}$ & NAD & NADP & NAD & NADP \\
\hline Hexadecane & 5.7 & 147.2 & 10.1 & 58.7 & 47.5 & 147.7 \\
\hline Hexadecanol & 8.5 & 43.5 & 9.5 & 35.9 & 2.9 & 14.7 \\
\hline Dodecyl aldehyde & 14.9 & 5.5 & 9.8 & 2.4 & 25.2 & 9.8 \\
\hline Ethanol & 51.3 & 13.8 & 20.4 & 7.5 & 1.3 & 3.7 \\
\hline Palmitate & 14.7 & 18.2 & 34.1 & 7.7 & 5.7 & 16.9 \\
\hline
\end{tabular}




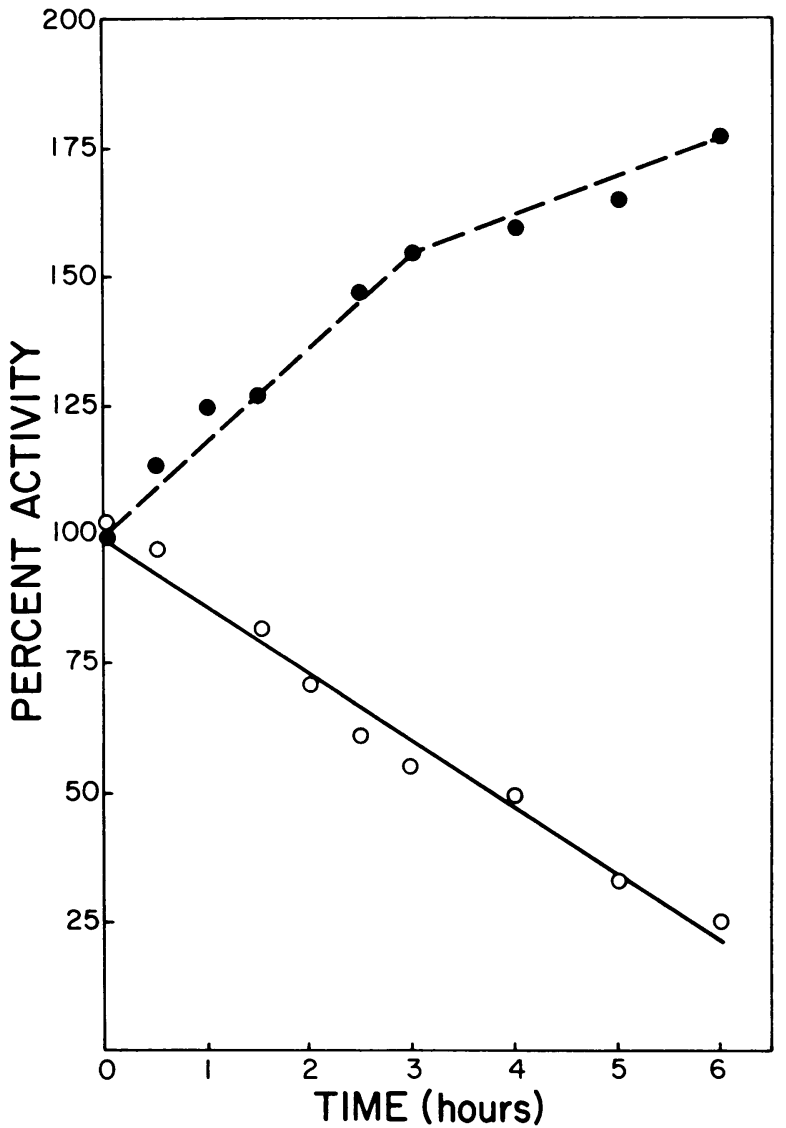

FIG. 2. Percent NAD (๑)- and NADP (O)-dependent FALDH activity remaining in crude extracts incubated at $58^{\circ} \mathrm{C}$ for the specified time. Crude extracts were derived from palmitate-grown cells exposed for $30 \mathrm{~min}$ to dodecyl aldehyde.

ential thermal stability of the two activities suggests that the NAD- and NADP-linked FALDH activities represent two different enzymes present in crude extracts.

Kinetic properties of NADP-linked FALDH. The soluble NADP-linked FALDH, present in crude extracts derived from hexadecane-, hexadecanol-, ethanol-, and palmitategrown cells, was precipitated with $50 \%$ ammonium sulfate. The precipitate was dissolved in $0.1 \mathrm{M}$ phosphate buffer $(\mathrm{pH} 7.5)$ at a 15-fold-higher protein concentration and was used for determination of the kinetic properties of the enzyme. The NADP-dependent FALDH exhibited similar apparent $K_{m}$ values for decyl aldehyde in extracts derived from hexadecane-, hexadecanol-, ethanol-, and palmitate-

TABLE 2 Kinetic properties of NADP-linked FALDH

\begin{tabular}{|c|c|c|c|}
\hline Growth substrate & $\begin{array}{c}\text { Sp. } \text { act }^{a} \\
(\mathrm{nmol} / \mathrm{min} / \mathrm{mg} \text { of protein) }\end{array}$ & 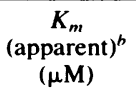 & $\begin{array}{c}V_{\max } \\
\text { (apparent) } \\
\text { (nmol/min) }\end{array}$ \\
\hline Hexadecane & 273.6 & 5.0 & 537.0 \\
\hline Hexadecanol & 331.7 & 13.0 & 500.0 \\
\hline Ethanol & 14.2 & 18.0 & 25.0 \\
\hline Palmitate & 29.2 & 18.3 & 38.0 \\
\hline
\end{tabular}

"Measured in the $50 \%$ ammonium sulfate precipitate of the soluble fraction.

${ }^{b} K_{m}$ for decyl aldehyde.

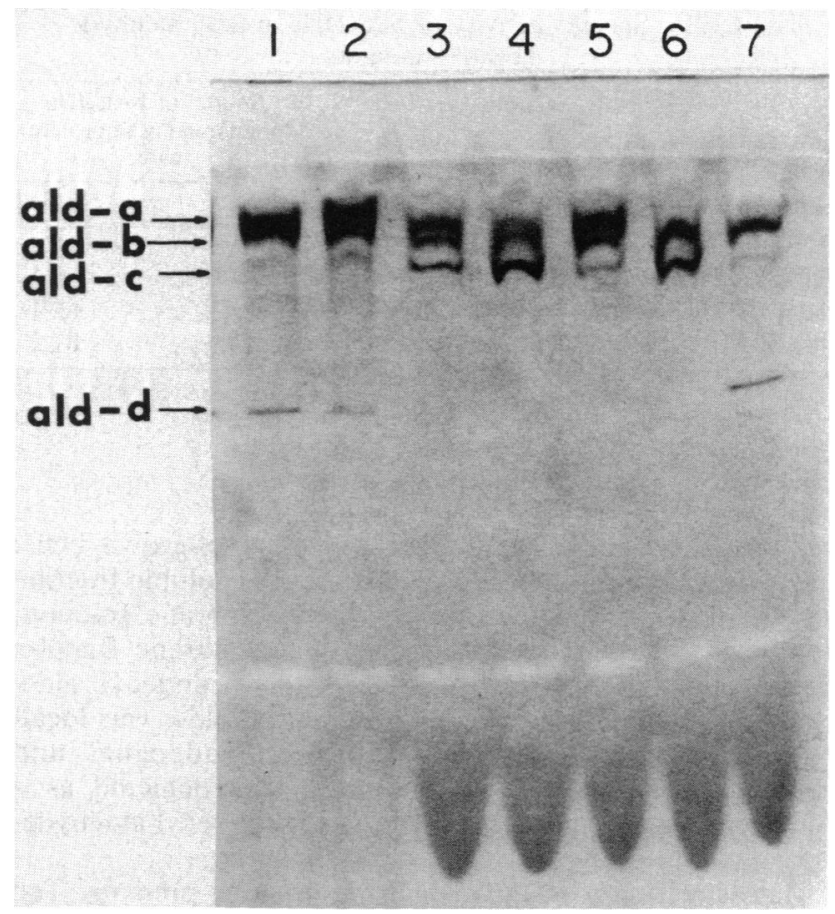

FIG. 3. Zymogram demonstrating aldehyde dehydrogenase activity in crude extracts derived from cells exposed to dodecyl aldehyde (lane 1), hexadecane (lane 3), hexadecanol (lane 5), and palmitate (lane 7). Lanes 2, 4, and 6 demonstrate FALDH activity in crude extracts derived from rifampin-treated dodecyl aldehyde-, hexadecane-, and hexadecanol-exposed cells, respectively. There is $25 \mu \mathrm{g}$ of protein per lane. Aldehyde dehydrogenase activity was detected with decyl aldehyde plus acetyladehyde as the substrates and NAD plus NADP as the cofactors.

grown cells (Table 2). The apparent $V_{\max }$ was 15 - to 20 -fold higher in extracts of hexadecane- or hexadecanol-grown cells than in those derived from ethanol- or palmitate-grown cells.

Detection of FALDH activity on zymograms. Multiple FALDH activity bands were detected on gels stained for FALDH activity in situ (Fig. 3). Crude extracts derived from hexadecane- and hexadecanol-grown cells exhibited identical FALDH banding patterns, with three FALDH isozymes detected, ald-a, ald-b, and ald-c. Crude extracts prepared from dodecyl aldehyde-grown cells exhibited ald-a, ald-b, and ald-d, while crude extracts derived from palmitategrown cells contained ald-b and ald-d. Each of the four isozymes reacted with either NAD or NADP as the cofactor and with either decyl aldehyde or acetylaldehyde as the substrate. Protein bands corresponding to ald-a, ald-b, ald-c, and ald-d were present in crude extracts of hexadecane-, hexadecanol-, dodecyl aldehyde-, and palmitate-grown cells, as detected by staining with Coomassie brilliant blue (data not shown).

Changes in the FALDH zymogram banding pattern were effected by pretreatment of cells with rifampin (Fig. 3). ald-a was absent or deficient in rifampin-treated hexadecane- and hexadecanol-induced cells, whereas the FALDH isozyme pattern remained unaltered in rifampin-treated dodecyl aldehyde-induced cells.

On zymograms, ald-a was localized exclusively in the membrane fraction in hexadecane- and dodecyl aldehydegrown cells, whereas ald-a was present in both the soluble 
TABLE 3. Specific activity of FALDHs in fatty aldehydenegative mutants

\begin{tabular}{llr}
\hline \multirow{2}{*}{\multicolumn{1}{c}{ Strain }} & \multicolumn{2}{c}{$\begin{array}{c}\text { Sp act }{ }^{\prime \prime} \text { of FALDHs } \\
\text { (nmol/min/mg of protein) } \\
\text { with: }\end{array}$} \\
\cline { 2 - 3 } & NAD & NADP \\
\hline Acinetobacter sp. strain HO1-N & 21.5 & 42.4 \\
Ald21 & 20.8 & 6.3 \\
Ald24 & 25.7 & 65.1 \\
Ald21R & 20.7 & 81.2 \\
\hline
\end{tabular}

" Measured in crude extracts of cells exposed to hexadecane for $8 \mathrm{~h}$. Values represent an average of three specific activity determinations.

and the membrane fractions of hexadecanol-grown cells. The electrophoretic mobility of ald-a in the soluble fraction was identical to that detected in the membrane fraction. ald-b was detected exclusively in the membrane fraction derived from hexadecane-, hexadecanol-, dodecyl aldehyde, and palmitate-grown cells. Similarly, ald-c was localized in the membrane fraction of hexadecane- and hexadecanol-grown cells, while ald-d was detected as a soluble isozyme in extracts derived from dodecyl aldehydeand palmitate-grown cells (data not shown).

Characterization of fatty aldehyde-negative mutants. Ten independently isolated fatty aldehyde-negative mutants $\left(\mathrm{Ald}^{-}\right)$were classified into two groups based on growth characteristics. All 10 mutants were dodecyl aldehyde negative and palmitate, acetate, and ethanol positive. Eight Ald $^{-}$mutants were hexadecane and hexadecanol negative (class 1), while two Ald $^{-}$mutants were hexadecane and hexadecanol positive (class 2). One mutant from each class was selected for further characterization, Ald21 (class 1) and Ald24 (class 2).

FALDH activity in Ald ${ }^{-}$mutants. The specific activities of NAD- and NADP-linked FALDHs in Ald ${ }^{-}$mutants were measured in palmitate-grown cells exposed to hexadecane (Table 3). In Ald21, the specific activity of the NAD-linked FALDH was similar to wild-type levels, while the NADPlinked FALDH was reduced sevenfold. In Ald24, the specific activity of the NAD-linked FALDH was similar to wild-type levels, while that of the NADP-linked FALDH was 1.5-fold higher (Table 3).

A spontaneous fatty aldehyde-positive revertant of Ald21, termed Ald21R, was isolated by plating Ald21 on minimal medium agar plates supplemented with dodecyl aldehyde vapors. Ald 21 reverted spontaneously to the fatty aldehydepositive phenotype at a frequency of $1.0 \times 10^{-6}$ and to the hexadecane-positive phenotype at a frequency of $5.0 \times 10^{-7}$. Ald21R was positive for growth on dodecyl aldehyde, hexadecane, and hexadecanol. The level of the NAD-linked FALDH in crude extracts derived from hexadecane-exposed Ald21R was similar to that of the wild-type strain, while the level of the NADP-linked FALDH was twofold higher (Table 3). Thus, growth on hexadecane, hexadecanol, and dodecyl aldehyde in Ald21R was correlated with the restoration of NADP-linked FALDH activity, indicating that the NADP-dependent FALDH activity is required for growth on those substrates.

Accumulation of radioactive products from oxidation of $\left[{ }^{3} \mathbf{H}\right]$ hexadecane. The distribution of radioactivity in products derived from the oxidation of $\left[{ }^{3} \mathrm{H}\right]$ hexadecane was determined in the $\mathrm{Ald}^{-}$mutants for comparison with the wild-type strain (Table 4). Ald21 accumulated $60 \%$ more fatty aldehyde and $61 \%$ less fatty acid than the wild-type strain plus similar levels of fatty alcohol and wax ester. Ald24 accumulated $27 \%$ more fatty aldehyde, $95 \%$ more fatty alcohol, and $65 \%$ more wax ester than the wild-type strain, with levels of fatty acid similar to those observed in wildtype cells. The reduced levels of fatty acid and the accumulation of fatty aldehyde derived from the oxidation of hexadecane correlate with the reduced levels of NADP-linked FALDH in hexadecane-exposed Ald21. The accumulation of fatty aldehyde in Ald24 is not correlated with a block in FALDH activity as shown by the normal or increased levels of NAD- and NADP-linked FALDH activity in hexadecaneexposed cells (Table 4) and by the normal levels of fatty acid produced from hexadecane. Thus, the inability of Ald24 to grow on hexadecane, hexadecanol, or dodecyl aldehyde is due to an unidentified mutation.

\section{DISCUSSION}

Acinetobacter sp. strain HO1-N contains three aldehyde dehydrogenases: (i) a membrane-bound, NADP-linked FALDH induced by growth on hexadecane, hexadecanol, and fatty aldehyde; (ii) a constitutive, membrane-bound, NAD-linked FALDH; and (iii) a soluble, NAD-linked ALDH induced by growth on ethanol (14).

The NAD- and NADP-linked FALDH activities exhibit a similar cellular distribution pattern. Both are membrane localized but are also detected as cytoplasmic activities. Extrinsic membrane proteins are often "solubilized" during French pressure cell lysis procedures, and these enzymes may fit into this category. The NAD- and NADP-linked FALDH activities appear to represent two separate enzymes on the basis of their differential thermal inactivation and differential physiological induction characteristics and by the isolation of $\mathrm{Ald}^{-}$mutants deficient in the NADP-linked but not the NAD-linked activity.

The NADP-dependent FALDH is required for growth of Acinetobacter sp. strain HO1-N on hexadecane, hexadecanol, and fatty aldehyde, since $\mathrm{Ald}^{-}$mutants deficient in this activity (class 1 ) were unable to grow on these substrates. The isolation of a fatty aldehyde-positive revertant of the Ald $^{-}$mutant, Ald21, provided evidence that the NADP-linked FALDH is essential for hexadecane, hexadecanol, and fatty aldehyde dissimilation. NADP-linked FALDH activity was restored to normal levels in the revertant, along with the ability of Ald21R to grow on hexadecane, hexadecanol, or fatty aldehyde as the sole source of carbon and energy. Ald ${ }^{-}$mutants with normal or increased levels of NADP-linked FALDH (class 2) were positive for growth on hexadecane and hexadecanol.

The NADP-linked FALDH described in this study resem-

TABLE 4. Products of $\left[{ }^{3} \mathrm{H}\right]$-hexadecane oxidation in fatty aldehyde-negative mutants

\begin{tabular}{|c|c|c|c|c|}
\hline \multirow{2}{*}{ Strain } & \multicolumn{4}{|c|}{$\begin{array}{l}{\left[{ }^{3} \mathrm{H}\right]-\text { hexadecane oxidation products }} \\
\left(\mathrm{pmol}{ }^{\prime /} / \mathrm{mg} \text { of cell protein }\right)\end{array}$} \\
\hline & $\begin{array}{l}{ }^{3} \mathrm{H} \text {-fatty } \\
\text { aldehyde }^{h}\end{array}$ & ${ }^{3} \mathrm{H}$-fatty acid ${ }^{b}$ & $\begin{array}{l}{ }^{3} \mathrm{H} \text {-fatty } \\
\text { alcohol }^{b}\end{array}$ & ${ }^{3} \mathrm{H}$-wax ester \\
\hline $\begin{array}{l}\text { Acinetobacter sp. } \\
\text { strain } \mathrm{HO} 1-\mathrm{N}\end{array}$ & 3.0 & 47.1 & 9.6 & 40.0 \\
\hline Ald 21 & 4.8 & 18.6 & 11.0 & 44.0 \\
\hline Ald 24 & 3.8 & 50.8 & 18.7 & 66.0 \\
\hline
\end{tabular}

a Picomoles of $\left[{ }^{3} \mathrm{H}\right]$-hexadecane converted into ${ }^{3} \mathrm{H}$-labeled product.

${ }^{b}$ Measured in saponified lipid samples.

'Measured in nonsaponified lipid samples. 
bles the NADP-dependent, membrane-bound aldehyde dehydrogenase induced in hexadecane- or hexadecanol-grown A. calcoaceticus $69 \mathrm{~V}$, described by Sorger and Aurich (15, 16). However, further biochemical evidence is required to compare the two enzyme activities.

The NAD-linked FALDH activity is expressed constitutively in this organism. The specific activity of the enzyme increased in fatty aldehyde-exposed cells, suggesting a dissimilatory role for this enzyme in fatty aldehyde metabolism. Rifampin treatment, however, did not affect the apparent induction, indicating that induction did not occur at the transcriptional level. The possibility of enzyme activation was not assessed. Mutants deficient in NAD-linked FALDH activity were not isolated. Thus, the role of this enzyme in the pathway of hexadecane, hexadecanol, and fatty aldehyde dissimilation cannot be definitely stated.

A third aldehyde dehydrogenase, ALDH, was distinguished from the FALDHs. ALDH activity is soluble, NAD-linked, and induced by growth on ethanol (14). The ethanol-inducible ALDH activity has been correlated with the ald-d isozyme detected in the soluble fraction of ethanolgrown cells (14). NAD- or NADP-linked FALDH activity is not coinduced with ALDH activity in ethanol-exposed cells. NAD-dependent ALDH is required for growth of Acinetobacter sp. strain HO1-N on ethanol (14). An ethanolnegative mutant, Eth3, deficient in ALDH activity was capable of growth on hexadecane, hexadecanol, and fatty aldehyde (14). Hexadecane-grown Eth3 had normal levels of both NAD- and NADP-linked FALDH activities (data not shown).

Four aldehyde dehydrogenase isozymes were resolved electrophoretically in crude extracts of Acinetobacter sp. strain HO1-N. The isozymes reacted with both long-chain $\left(C_{10}\right)$ and short-chain $\left(C_{2}\right)$ aldehydes and with both NAD and NADP, indicating a broad substrate specificity and a nonspecificity for the pyridine nucleotide cofactor. The presence of multiple aldehyde dehydrogenases within a single bacterial strain is not unique to Acinetobacter sp. Heptane-grown $P$. aeruginosa Sol20 contains an NAD(P)dependent soluble aldehyde dehydrogenase as well as a membrane-bound, NAD-linked aldehyde dehydrogenase (3). Two different constitutive soluble aldehyde dehydrogenases, one NAD linked and the other NADP linked, were isolated from glucose-grown $P$. aeruginosa $196 \mathrm{~A}$, and a membranebound, NAD-dependent aldehyde dehydrogenase was also detected in heptane- or hexadecane-grown cells of the same strain (8).

Acinetobacter sp. strain HO1-N appears to possess constitutive and inducible enzyme systems for the oxidation of fatty aldehyde. Intact cells oxidize fatty aldehyde constitutively, whereas fatty aldehyde is oxidized in vitro by both constitutive (NAD-dependent FALDH) and inducible (NADP-dependent FALDH) enzymes. Similarly, hexadecanol is oxidized constitutively in intact cells, while hexadecanol dehydrogenase appears to be inducible (14). In hexadecane-exposed cells, the prolonged lag period before NADP-dependent FALDH induction corresponds to the extended induction period $(3 \mathrm{~h})$ preceding hexadecane oxidation (14). Thus, hexadecane does not induce FALDH, but rather a product of hexadecane oxidation (fatty alcohol or fatty aldehyde) acts as the inducer molecule. Preliminary evidence has shown that NADP-dependent FALDH was not induced in hexadecane-exposed, alkane-negative (Alk ${ }^{-}$) $\mathrm{mu}^{-}$ tants, but the enzyme was induced in fatty aldehyde-exposed cells. The $\mathrm{Alk}^{-}$mutants were unable to oxidize hexadecane but were capable of growth on fatty aldehyde, fatty alcohol, and palmitate. These mutants appear to be blocked in one of the initial steps of hexadecane oxidation (unpublished observations).

The isolation of a nonanal-negative mutant which was octane negative in $P$. putida PpG6, carrying the wild-type OCT plasmid, has established that aldehyde is an obligatory metabolic intermediate in octane dissimilation in $P$. putida (7). This study provides genetic and physiological evidence confirming the role of fatty aldehyde as an essential metabolic intermediate and NADP-linked FALDH as a key enzyme in the dissimilation of hexadecane, hexadecanol, and fatty aldehyde in Acinetobacter sp. strain HO1-N.

\section{ACKNOWLEDGMENTS}

Appreciation is extended to Eva Nemeth, who provided excellent technical assistance, and to J. T. Singer for providing the alkane-negative mutants used in this study.

This work was supported in part by Public Health Service grant GM29086 from the National Institutes of Health.

\section{LITERATURE CITED}

1. Aurich, H., and G. Eitner. 1977. Induktion der NADP ${ }^{+}$. abhängigen Aldehyddehydrogenase durch Kohlenwasserstoffe bei Acinetobacter calcoaceticus. Z. Allg. Mikrobiol. 17:263266.

2. Baptist, J. N., R. K. Gholson, and M. J. Coon. 1963. Hydrocarbon oxidation by a bacterial enzyme system. I. Products of octane oxidation. Biochim. Biophys. Acta 69:40-47.

3. Bertrand, J. C., M. Gallo, and E. Azoulay. 1973. Aldehyde deshydrogenase soluble et particulaire de Pseudomonas aeruginosa. Biochimie 55:343-350.

4. Folch, J., M. Lees, and G. H. Sloane Stanley. 1957. A simple method for the isolation and purification of total lipides from animal tissues. J. Biol. Chem. 226:497-509.

5. Gallo, M., B. Roche, L. Aubert, and E. Azoulay. 1973. Distribution des enzymes et des cytochromes de Candida tropicalis cultive sur alcanes. Biochimie 55:195-203.

6. Gmünder, F. K., O. Kappeli, and A. Fiechter. 1981. Chemostat studies on the hexadecane assimilation by the yeast Candida tropicalis. Eur. J. Appl. Biotechnol. 12:135-142.

7. Grund, A., J. Shapiro, M. Fennewald, P. Bacha, J. Leahy, K. Markbreiter, M. Nieder, and M. Toepfer. 1975. Regulation of alkane oxidation in Pseudomonas putida. J. Bacteriol. 123:546-556.

8. Guerrillot, L., and J.-P. Vandecasteele. 1977. Purification and characterization of two aldehyde dehydrogenases from Pseudomonas aeruginosa. Eur. J. Biochem. 81:185-192.

9. Lebeault, J. M., B. Roche, Z. Duvnjak, and E. Azoulay. 1970. Isolation and study of the enzymes involved in the metabolism of hydrocarbons by Candida tropicalis. Arch. Microbiol. 72:140-153.

10. Lebeault, J. M., B. Roche, Z. Duvnjak, and E. Azoulay. 1970. Alcool et aldehyde deshydrogenases particulaires de Candida tropicalis cultive sur hydrocarbures. Biochim. Biophys. Acta 220:373-385.

11. Liu, C.-M., and M. J. Johnson. 1971. Alkane oxidation by a particulate preparation from Candida. J. Bacteriol. 106:830834.

12. Makula, R. A., and W. R. Finnerty. 1970. Microbial assimilation of hydrocarbons. Identification of phospholipids. J. Bacteriol. 103:348-355.

13. Singer, M. E., and W. R. Finnerty. 1984. Microbial metabolism of straight-chain and branched alkanes, p. 1-59. In R. M. Atlas (ed.), Petroleum microbiology. MacMillan Publishing Co., New York.

14. Singer, M. E., and W. R. Finnerty. 1985. Alcohol dehydrogenases in Acinetobacter sp. strain HO1-N: role in hexadecane and hexadecanol metabolism. J. Bacteriol. 164:1017-1024. 
15. Sorger, H., and H. Aurich. 1978. Oxydation von homologen aliphatischen Aldehyden durch membrangebundene und solubilisierte Aldehyddehydrogenase aus Acinetobacter calcoaceticus. Z. Allg. Mikrobiol. 18:587-591.

16. Sorger, H., and H. Aurich. 1978. Mikrobielle Aldehyddehydrogenasen und ihre bedeutung für die assimilation ali- phatischen Kohlenwasserstoffe. Wiss. Z. Karl-Marx-Univ. Lepizig Math.-Naturwiss. Reihe 27:35-45.

17. Yamada, T., H. Nawa, S. Kawamoto, A. Tanaka, and S. Fukui. 1980. Subcellular localization of long-chain alcohol dehydrogenase and aldehyde dehydrogenase in n-alkane-grown Candida tropicalis. Arch. Microbiol. 128:145-151. 